Research Article

\title{
Ecological Security Evaluation of Marine Ranching Based on DEMATEL-Fuzzy Comprehensive Evaluation
}

\author{
Yuan-Wei Du $\mathbb{D}^{1,2}$ Jing Fang $\mathbb{D}^{1}$, and Ping Wang $\mathbb{D}^{3}$ \\ ${ }^{1}$ Management College, Ocean University of China, Qingdao 266100, China \\ ${ }^{2}$ Marine Development Studies Institute of OUC, Key Research Institute of Humanities and Social Sciences at Universities, \\ Ministry of Education, Qingdao 266100, China \\ ${ }^{3}$ Business School, Qingdao University, Qingdao 266100, China \\ Correspondence should be addressed to Ping Wang; 6240821@qq.com
}

Received 17 December 2020; Revised 7 January 2021; Accepted 31 January 2021; Published 25 February 2021

Academic Editor: Shouzhen Zeng

Copyright ( 2021 Yuan-Wei Du et al. This is an open access article distributed under the Creative Commons Attribution License, which permits unrestricted use, distribution, and reproduction in any medium, provided the original work is properly cited.

\begin{abstract}
Marine ranching plays an integral role in providing fishery resources. Given the critical importance of protecting the marine ecological system, the ecological security evaluation of marine ranching is significant. However, the existing research rarely involves marine ranching ecological security (MRES) evaluation and does not provide a complete evaluation index system. The purpose of the present study was to estimate MRES through several steps and evaluate it scientifically by fully considering the relationship between the factors. First, the evaluation index system was structured using the Driver-Pressure-State-ImpactResponse (DPSIR) framework by following certain principles. Second, the study applied the Decision Making Trial and Evaluation Laboratory (DEMATEL) method and fuzzy comprehensive evaluation (FCE) method to assess MRES. Third, a case study of a marine ranching in the Shandong Province was discussed to demonstrate the applicability of the proposed method. This also illustrated the steps of the evaluation. In this case study, the result of the MRES evaluation was graded as excellent. The results demonstrate that using these methods to evaluate MRES can account for the complex relationships between the factors and the cognitive ability of the experts and thus integrate the experts' information comprehensively, which adds to the credibility of the evaluation results.
\end{abstract}

\section{Introduction}

The continuous growth of the human population calls for high-quality protein. There has been an increasing demand for marine products, which has stressed fishery production. Severe problems, such as the deterioration of the coastal environment and the rapid decline in biological resources, have materialized along with the intervention of human activities [1]. These issues have made people realize the value of protection of marine bioresources and fostered the idea of marine ranching, which can enable the artificial production of economic marine life. The importance of marine ranching lies in part in its potential to increase the harvest capacity of many species and to carry out planned and purposeful production of the marine resources.
A marine ranch is concerned with the sustainable development of marine ecology, marine economy, and fishery production. Several countries, such as China [2], Japan [3], Australia [4], and Norway [5], consider marine ranching as the most promising method to increase fishery resources and stock, and promote sustainable development of fishery resources. In recent years, many researchers have noticed the important role of marine ranching. These inquiries usually study the following three aspects. First, the concept of marine ranching is defined in a variety of forms in different studies. For example, Zhang et al. held the view that marine ranching is a type of mariculture industry that adopts scientific principles to cultivate and manage fishery resources [6]. Grant et al. regarded that marine ranching involves releasing hatchlings into the wild. However, it is desirable to capture them before they breed or mate with wild individuals 
[7]. Kitada explained that the purpose of marine ranching is to catch (to the extent possible) all juvenile fish released in the fishing area, which can be managed by fishermen [3]. Second, several researchers have explored the effective allocation method based on the breeding species of marine ranching. For example, Hadas et al. focused on two methods to evaluate sponge cultivation in marine ranching along with environmental factors, with the aim of improving the quality of life and the yield of the sponge [8]. Taylor et al. explored an effective way to dispose of artificially cultured sea cucumbers under the environmental conditions in northern Australia [4]. Liang et al. showed the natural process-dependent effects of shellfish cultures [9]. Third, marine ranching has different impacts on economy, resources, and environment, among others. For example, Moksness and Støle used the net present value approach to calculate the profitability of marine ranching and explored the factors that affect the profitability of marine ranching activities [5]. Kim et al. adopted a singleregion model and a multi-region input-output model to calculate the intraregion and interregion economic impacts of marine ranching [10]. Lee and Zhang applied ecological models (Ecopath, Ecosim, and Ecospace) to evaluate the impact of marine ranching activities on the ecosystem [11]. Grant pointed out that mariculture, including marine ranching, may affect wild populations in several ways and lead to dynamic genetic risks [7].

Ecological security is playing an increasingly significant role in national security and social stability. Ecological security is a complicated system involving natural, landscape, and socioeconomic factors [12]. Ecological security evaluation, which refers to a description of the quality of an ecological environment system and its security status, is a popular research topic $[13,14]$. Previously, researchers mainly studied the ecological security evaluation of a region [15], city [16], marine body [17], basin [18], or land [19] from the perspective of ecological early warnings [20], ecological risk [21], or landscape pattern [22]. Although various evaluation approaches have been adopted to address the issue of ecological security in the above fields, the evaluation index systems are constructed by following the framework of the Pressure-State-Response (PSR) model or its extensions $[20,23]$, and evaluation methods are frequently constructed from multiple criteria decision-making (MCDM) [24-28]. For example, Li et al. proposed a Decision Making Trial and Evaluation Laboratory (DEMATEL) method for probabilistic linguistic term sets to analyze relations of criteria and find key factors in the evaluation system [29]. Ruan et al. proposed an evaluation model of tourism ecological security based on the Driver-Pressure-State-Impact-Response (DPSIR) and data envelopment analysis (DEA) methods in order to evaluate the quality of tourism ecological security from the perspective of efficiency [30]. Han et al. used a fuzzy comprehensive evaluation (FCE) method to calculate, analyze, and evaluate the urban ecological security level from 2003 to 2012 and used the entropy weight method to calculate the index weight [31]. Jiang established an FCE model of urban ecological security and used membership degree to express the evaluation and description of ecological security [32]. Solovjova presented an ecological risk assessment method for the marine ecosystem and a mathematical model under the joint action of natural and human factors [33]. Li and Wei proposed an emergency decision-making style based on D-S evidence theory [34]. Zeng et al. indicated that the information for business decisions is often vague and imprecise, and developed a fuzzy methodology for sustainable supplier selection based on fuzzy information [35].

Many researchers have focused their attention on the problem of marine ranching, and they have carried out valuable research on the above-discussed three aspects. With respect to ecological security, scholars have also reported results in several areas, including regional ecological security and ecological security evaluation. The abovementioned research has expanded the theory of marine ranching and the methods of ecological security. However, few scholars have paid attention to the problem of marine ranching ecological security (MRES). Although previous studies have focused on MRES and its influence paths, they have not paid attention to how to evaluate it [36]. MRES is the overall balance between the resource structure of the marine ranching artificial ecosystem and the marine environment. It maintains environmental protection, resource conservation, and sustainable output of fishery. MRES is significant for the ecological benefit and sustainable development of marine ranching. In particular, MRES can affect the sustainable development of marine resources under the condition of satisfying three aspects, namely, resource supply, ecological environment, and human needs. A safe marine ranching ecological system is conducive to improving the quality of resource supplies and the restoration ability of the ecological environment, thus helping to maximize ecological benefits while ensuring economic benefits and social benefits. The motivation of the present paper is to propose an evaluation mechanism for MRES based on DEMATEL and FCE. The proposed approach focuses on solving the following aspects of these problems:

The first is how to construct an evaluation index system for MRES. The marine environment is a complex and dynamic system, and MRES results from numerous interactions. Thus, there is a need to construct a systematic evaluation index system for evaluating it. It is worth noting that recent studies [37] have found several advantages in applying the PSR framework to coastal or marine systems studies. This framework does not reflect the Driver $(D)$ and Impact $(I)$ factors. The DPSIR framework was proposed to allow wide application; it is more conducive for identifying the root causes of pressure on ecosystems [38]. Furthermore, the DPSIR framework is more systematic and comprehensive compared with the PSR [1]. Traditionally, the DPSIR framework, which has the potential to describe the relationship between human activities and ecological environmental problems, has been used to study the processes of complex coastal systems and marine management [39]. It is recognized as mature and appropriate for coastal systems. Consequently, in this paper, the MRES evaluation index system is set and organized based on the DPSIR framework and its five aspects.

The second one is how to reflect influence relationships between evaluation indices in MRES. Marine ranching is an 
artificial ecosystem, and its MRES is a functional state produced by the interaction of internal factors. According to the complex system theory [40], the factor state in the system and the structural relationship between the factors jointly determine the function of the system. Speaking concretely, the performance value of a particular marine ranching enterprise (MR-E) of each evaluation index represents the factor state, and the influence between the evaluation indices represents the structure of the factors. Thus, MRES is the overall performance of the system function. If we only consider the state of the factors and ignore the relationship between the factors in the process of MRES evaluation, then the influence of system structure on system function is neglected, and the overall MRES results of the evaluation objects are flawed. With regard to this, an effective evaluation method should be used to enhance decision quality. Fortunately, the DEMATEL method is powerful for solving MCDM problems. Unlike other MCDM methods, the DEMATEL method can describe the strength of the relationship between factors. Understanding the causes and the influencing factors is conducive to comprehensive decision-making by stakeholders [41]. It is an effective method for factor analysis and identification, which refers to making full use of experts' experience and knowledge to analyze complex systems; it also reveals the causal relationship between the components [42]. With rich expert knowledge, the interrelation and overall influence of various factors can be analyzed better to identify the structural relationships within the complex system, which is again conducive to comprehensive decision-making by stakeholders. Furthermore, it provides methodical guidance for solving the complex system problem of MRES evaluation $[42,43]$. Considering the unique advantages of the approach, the present paper utilizes the DEMATEL method to reflect the influence of relationships of the evaluation indices in MRES.

The third one is how to make evaluations for MRES by combining subjective experience and objective data. A realistic evaluation of marine ranching is generally carried out not only through an MR-E submitting self-evaluation reports on specific issues but also by the government organizing several experts in relevant fields to conduct a group evaluation (MRES should not be an exception). For example, the annual evaluation method for China's national marine ranching demonstration zones stipulates that the management and maintenance personnel of the demonstration zone shall organize and summarize the relevant information of the marine ranching that year and then write its annual work report. The provincial department in charge of fishery must utilize more than five experts to make a comprehensive evaluation of the construction and operation of the demonstration area based on the annual work report and relevant information. This paper holds that the above evaluation process has significant reference value for MRES evaluation, but the following two issues should also be paid attention to in the implementation process. Firstly, in the self-evaluation report, the MR-E should be required to provide objective data on the lowest indices to the extent possible (called MR-E self-evaluation). The MR-E is the direct operator of marine ranching and can be reasonably expected to provide accurate data. For example, the MR-E can provide data on the marine environment, biological resources, and other indices based on the lowest level indices such as target biomass and biodiversity index. As the MR-E is required to only provide objective data for the bottom indices rather than make evaluations, it is conducive for the reduction of self-interest behavior. Secondly, although experts should be invited to carry out MRES evaluation based on the underlying objective data, one must also rationally examine the experts' evaluation ability. The knowledge backgrounds of experts are different, and their judgments on the same problem may also differ. If the evaluation results of individual experts are simply weighted and averaged as group results, the accuracy of evaluation results may be affected owing to information loss. While experts can evaluate relatively simple problems, it is difficult to judge relatively complex problems because there are complicated correlation and influence relations between factors. For example, based on the previous two bottom-level index data samples, experts can easily judge the performance of the evaluation object (MR-E) on the State (S). However, because of the complex action mechanism among the five dimensions of DPSIR, it is difficult to make a comprehensive judgment on the overall performance of the MR-E. Therefore, we should aim to ensure that the problem of direct evaluation by experts is simple enough in the evaluation process. The FCE method presents qualitative results in a quantitative form based on the theory and mathematics of the membership degree of the model. It uses fuzzy mathematics to make an overall evaluation of things or objects subject to various factors $[44,45]$. To a certain extent, it avoids the possibility that the evaluation results may be influenced by the subjective feelings of experts, thus further improving the objectivity and credibility of the evaluation results [46]. This approach, which provides a comprehensive and scientific method for MRES, can solve issues that are fuzzy and difficult to quantify and is suitable for solving various nondeterministic problems [47]. Therefore, this paper combines MR-E self-evaluation with expert evaluation and constructs an MRES evaluation method by introducing the FCE method.

The structure of the paper is as follows. The evaluation index system of MRES based on the DPSIR model is presented in Section 2. The evaluation mechanism is proposed in Section 3. In Section 3, DEMATEL-FCE methods are applied to expound the evaluation steps of MRES evaluation. An illustrative case is in Section 4 to demonstrate the applicability of the proposed method. Section 5 concludes the paper.

\section{Evaluation Index System}

The index system is the basis of MRES evaluation. Its construction may impact the effectiveness of the evaluation results. As mentioned in section 1, MRES is the overall performance of the system function, and it is related to aspects such as marine environment, marine resources, and their interaction mechanism. This study mainly constructs the evaluation index system of MRES from the three 
objectives of biosafety, environmental safety, and ecosystem safety. These three types of factors have mutual influence and functions, which are affected by socioeconomic activities. To fully reflect the action mechanism between the factors, this paper constructs the MRES evaluation index system according to the DPSIR framework.

The steps to construct the index system are as follows. (1) Collect possible indicators. The literature provides the basis for the selection of indicators [36, 48-51]. The annual evaluation system of the national marine ranching demonstration areas helps in index selection. Thus, several possible indicators are achieved by the above ways. (2) Sort out the indicators. Based on the DPSIR framework, classify the collected indicators along five dimensions (Driver, Pressure, State, Impact, and Response). (3) Determine the MRES evaluation index system. Through research and consultation with experts and following the principles of systematic, comprehensive, forward-looking, and data accessibility [52], the indices are continuously adjusted, eliminated, and supplemented, and 32 evaluation indices of 13 categories for MRES are finally determined, as shown in Figure 1. For convenience, in this paper, the first-level indicator is expressed by factor $\left(\mathrm{C}_{i}, i=1, \ldots, I\right)$, the secondlevel indicator by element $\left(\mathrm{C}_{i j}, i=1, \ldots, I, j=1, \ldots J\right)$, and the third-level indicator by index $\left(\mathrm{C}_{i j k}, i=1, \ldots, I, j=1, \ldots, J, k=1, \ldots, K\right)$. The hierarchy of the indicators can be defined as factors on level 1, elements on level 2, and indices on level 3. To simplify the evaluation problem and enhance the reliability of the evaluation information in the actual evaluation process, the indices on level 3 are regarded as the interpretation of the upper-level index, and thus, the established indices on level 3 are the detailed explanations of the elements on level 2. In other words, the indices on level 3, which are a further explanation of the elements on level 2, are helpful for a comprehensive understanding of the current situation of the MRES. It provides clarity of the elements on level 2:

(1) Driver $\left(C_{1}\right)$ is the core of factors such as high living standards and ecological security. In the present study, the Driver mainly describes the potential factors that cause the change of MRES. The Driver factor is divided into three types of elements: policy driver $\left(c_{11}\right)$, economic driver $\left(c_{12}\right)$, and responsibility driver $\left(c_{13}\right)$. Among them, policy support $\left(c_{111}\right)$ and the laws and regulations system $\left(c_{112}\right)$ influence the policy driver situation. That is, the formulation, improvement, and implementation of policies play a vital role in maintaining MRES. They provide a significant basis for decision-making regarding the marine ranching production mode. In addition, the special financial fund input $\left(c_{121}\right)$, government subsidies $\left(\mathrm{c}_{122}\right)$, and the economic incentives of the profit margin $\left(c_{123}\right)$ of the MR-E itself, which are the economic factors inside and outside the enterprises, are also powerful driving forces for the MR-E to carry out ecological security maintenance. To some extent, the enterprise's ecological awareness $\left(c_{131}\right)$ also subtly influences decision-making. The proportion of investment in environmental protection funds reflects the importance that the MR-E assigns to eco-environmental protection. Media messaging would also benefit the MR-E, i.e., the wider its media influence, the greater are the potential incentives for an MR-E, which may prompt the MR-E to make more positive changes in order to maintain the reputation of the marine ranching brand.

(2) Pressure $\left(C_{2}\right)$ is mainly the result of one or more activities. It can cause changes in the natural system (State). The Pressure factor includes two types of elements: development pressure $\left(c_{21}\right)$ and environmental pressure $\left(c_{22}\right)$. The application efficiency of policies and funds affects the output of marine ranching construction and is mainly reflected in the numbers of bottom sowing and proliferation and release $\left(c_{211}\right)$, seaweed field and seagrass bed transplant cultivation $\left(c_{212}\right)$, and artificial reef construction and maintenance $\left(c_{213}\right)$. Moreover, the degree of greenness of the farming method $\left(c_{214}\right)$ affects the status of the MRES. The type of cage input affects the aquatic ecology and operational efficiency of marine ranching. Modern large-scale, intelligent deep-water cages and large-scale ecological fences can be considered efficient. Water pollution $\left(c_{221}\right)$ may occur during construction and routine maintenance, and uncontrollable natural disasters $\left(c_{222}\right)$ may also change the state of marine ecological security.

(3) State $\left(C_{3}\right)$ relates to changes in the present natural situation as a result of Driver $\left(C_{1}\right)$ and Pressure $\left(C_{2}\right)$. In the present study, the State factor includes two types of elements: marine environment $\left(c_{31}\right)$ and biological resources $\left(\mathrm{c}_{32}\right)$. According to the "GB 3097-1997 Seawater Quality Standards," it is possible to judge the standards reached by the water quality of the water in which the MR-E is located. Moreover, according to the "GB 18668-2002 Marine Sediment Quality Standards," the status of marine sediments in the sea area of the MR-E can also be judged. Water quality $\left(c_{311}\right)$ and marine sediments $\left(c_{312}\right)$ can reflect the quality of the marine environment. Target biological resources $\left(c_{321}\right)$ and biodiversity index $\left(c_{322}\right)$ reflect the level of biological resources to a certain extent, and they can be judged according to the "SC/ T9417-2015 Technical Specifications for the Evaluation of the Conservation Effect of Artificial Reef Resources."

(4) Impact $\left(\mathrm{C}_{4}\right)$ is the outcome of changes in both natural and anthropogenic states [48]. It is mainly manifested in the final result of ecological security changes through Driver $\left(\mathrm{C}_{1}\right)$, Pressure $\left(\mathrm{C}_{2}\right)$, and State $\left(\mathrm{C}_{3}\right)$. The Impact factor can be measured through three types of elements: ecological impact $\left(c_{41}\right)$, social impact $\left(c_{42}\right)$, and economic impact $\left(c_{43}\right)$. Specifically, the ecological change of marine ranching can be reflected by the improvement of water quality $\left(\mathrm{c}_{411}\right)$, the cultivation and restoration 


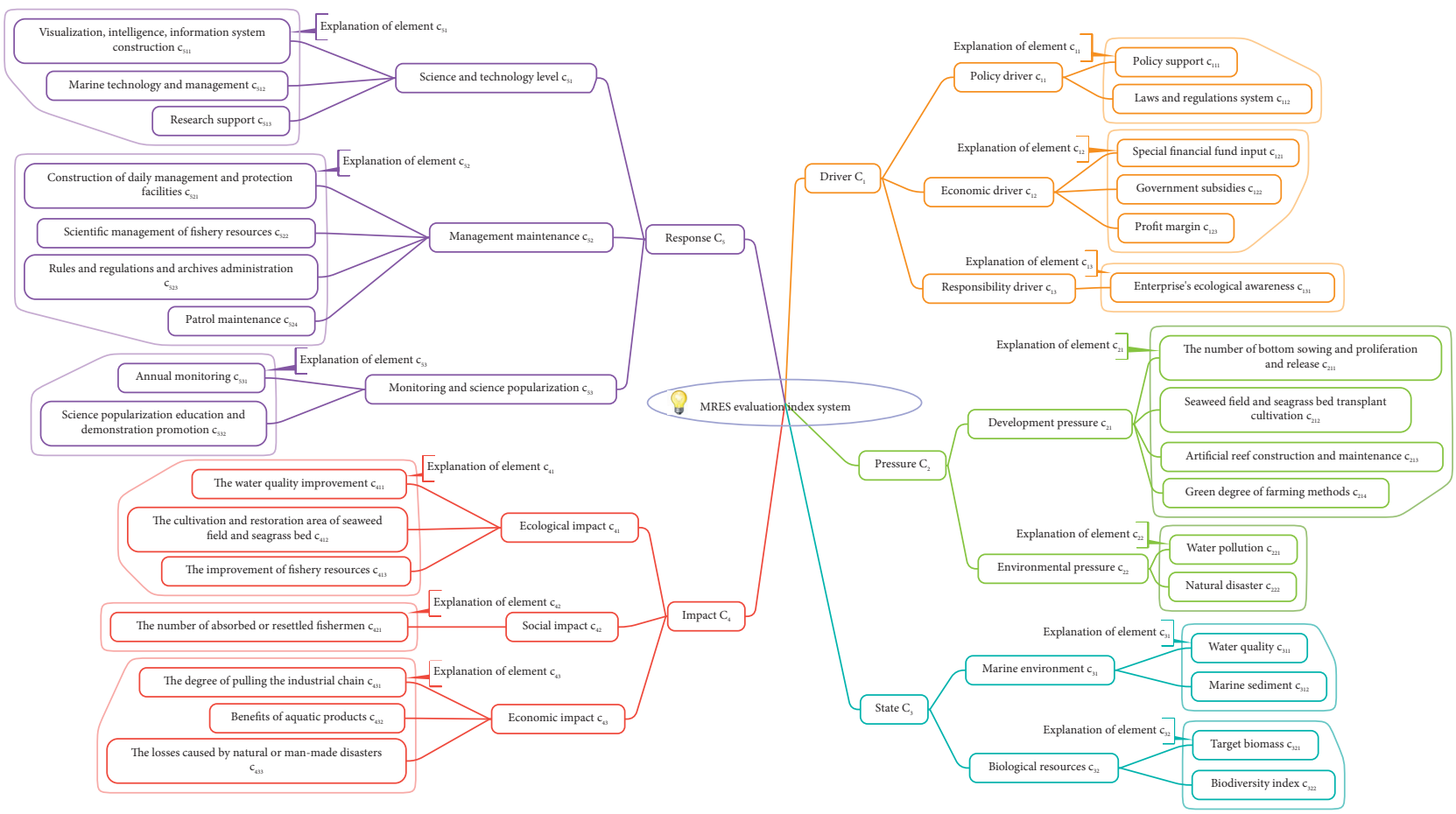

Figure 1: The evaluation index system for MRES.

area of seaweed field and seagrass bed $\left(\mathrm{c}_{412}\right)$, and the improvement of fishery resources $\left(c_{413}\right)$ relative to the situation in the previous year. If the survival area of the seaweed field or seagrass bed transplanting accounts for more than one-fifth of the total area of marine ranching, it can be seen as having a good impact. The social impact is mainly reflected in the situation of employment in the surrounding areas, namely, the number of absorbed or resettled fishermen $\left(c_{421}\right)$. On the economic side, if the MR-E creates a new mode of management that can be promoted more widely, it will attract many different enterprises and achieve cooperation, which can result in an economic effect. Based on this, the degree to which the development of the MR-E drives the relevant businesses of the upstream and downstream enterprises of the industrial chain and related enterprises associated with the industrial chain $\left(\mathrm{c}_{431}\right)$ can be taken as one of the indices of economic impact. The benefits of aquatic products $\left(\mathrm{c}_{432}\right)$ and the losses caused by natural or man-made disasters $\left(c_{433}\right)$ can be regarded as positive or negative economic impacts, respectively.

(5) Response $\left(\mathrm{C}_{5}\right)$ arises with the changes of MRES. They are active countermeasures taken by the MR-E to prevent ecological deterioration, reduce resource waste, improve biodiversity, and adapt to unexpected changes of the environmental state. The Response factor is mainly reflected by three types of elements: science and technology level $\left(c_{51}\right)$, management maintenance $\left(c_{52}\right)$, and monitoring and science popularization $\left(c_{53}\right)$. Specifically, technological innovation is a strong driving force for ecologically healthy development of marine ranching. It provides reliable guarantees for avoiding ecological risks and improving operational efficiency. In this paper, visualization, intelligence, information system construction $\left(c_{511}\right)$, marine technology and management $\left(c_{512}\right)$, and research support $\left(c_{513}\right)$ are regarded as the aspects to measure the scientific and technological level of marine ranching. Daily management and maintenance can achieve timely stop-loss and reasonable management of resources. It is mainly reflected in the construction of daily management and protection facilities $\left(c_{521}\right)$, scientific management of fishery resources $\left(c_{522}\right)$, rules and regulations and archives administration $\left(c_{523}\right)$, and patrol maintenance $\left(c_{524}\right)$. In addition, the results of annual monitoring $\left(c_{531}\right)$ play an important role in the development of MRES, including the number of monitoring activities on resources and the environment and the number of monitoring of technology reports. Science popularization and education $\left(c_{532}\right)$ can help publicize and promote the achievements of marine ranching.

\section{Evaluation Method for MRES}

3.1. Evaluation Mechanism. MRES evaluation is a process to determine the MRES grade by extracting and integrating the performance data of an MR-E in the five dimensions of DPSIR. In order to make evaluations for the MRES by combining subjective experience and objective data, it is 
necessary to carry out self-evaluation first, then expert evaluation, and finally comprehensive integration. (1) Selfevaluation is a process of obtaining the performance data of the MR-E on various underlying elements of MRES. As the MR-E is the main body of marine ranching operation, it has the best understanding of the actual situation of marine ranching. Therefore, it can provide objective underlying performance data. (2) Expert evaluation is a process to evaluate the performance of the MR-E on factors based on the objective data provided through the self-evaluation. Since the objective data gives the basis and the evaluation question is simple enough, the expert can independently provide scientific evaluation results. (3) Comprehensive integration is a process of integrating the evaluation information given by experts and the influence relationships among factors to determine the overall performance level of the evaluated MR-E on MRES.

In the evaluation of MRES in this study, three methods (DPSIR, DEMATEL, and FCE) are applied. DPSIR can not only provide an index system for self-evaluation and expert evaluation but also provide a basis for reflecting the influence relationships between factors. The role of DEMATEL is to determine the weights of the factors by combining the influence relationships between factors reflected by DPSIR. The function of FCE is to comprehensively integrate the evaluation results of the MR-E given by all experts on various factors and determine the overall performance grade of the MR-E on MRES.

The evaluation mechanism for MRES as described above is shown in Figure 2.

3.2. Self-Evaluation and Expert Evaluation. Self-evaluation is an objective description of each element of the marine ranching across all indices covered by the MR-E. Assume that the MR-E conducts a self-evaluation on the performance of marine ranching on $c_{i j}$, which includes index $\mathrm{c}_{i j 1}, \ldots, \mathrm{c}_{i j K_{i j}}$. Then, the MR-E can describe the specific performance on $c_{i j}$ according to the objective and realistic situation in terms of resources, environment, management, and other aspects. The self-evaluation can be expressed as follows:

Question: How does the marine ranching perform on $\mathrm{c}_{i j}$ ?

Answer: The performance of marine ranching on $c_{i j 1}$ is fact $_{i j 1}$, the performance on $c_{i j 2}$ is fact ${ }_{i j 2}, \ldots$, the performance on $c_{i j K_{i j}}$ is fact $_{i j K_{i j}}$.
Therefore, the self-evaluation results given by the MR-E on $c_{i j}$ can be expressed as $X_{i j}=\left\{\right.$ fact $_{i j 1}$, fact ${ }_{i j 2}$, $\ldots$, fact $\left._{i j K_{i j}}\right\}, \quad i=1, \ldots, 5, j=1, \ldots, J_{i}$.

Taking development pressure $\left(c_{21}\right)$ as an example, this element includes four indices (see Figure 1). This study aimed to determine the performance of marine ranching on $c_{21}$. Investigation of the MR-E revealed the following.

fact $_{211}$ : on bottom sowing and proliferation and release $\left(c_{211}\right)$, the annual number of proliferating and releasing streams or subsiding is $20 \mathrm{million} / \mathrm{year}$. There is evidence that the target organisms of the enterprise's proliferating and releasing streams have established self-breeding populations in this sea area.

fact $_{212}$ : on seaweed field and seagrass bed transplant cultivation $\left(c_{212}\right)$, the MR-E has carried out the construction of a seaweed farm or seagrass bed that has been transplanted and cultivated. The planting area of this year is 1 hectare.

fact $_{213}$ : on artificial reef construction and maintenance $\left(c_{213}\right)$, the MR-E has undertaken an artificial reef construction project. The artificial reef release area this year is $163 \mathrm{ha}$, and the release reef types are proliferative reef and swim fishing reef. In the past three years, side sweep sonar has been used for artificial reef inspection. fact $_{214}$ : on degree of greenness of farming method $\left(c_{214}\right)$, the production model that is adopted by the enterprise is a multi-nutrient-level comprehensive breeding mode, and the type of cage put into use in the marine ranching is an ordinary cage with 26 cages.

Therefore, the self-evaluation results on $c_{21}$ can be expressed as: $X_{21}=\left\{\right.$ fact $_{211}$, fact fl2 $_{21}$, fact $_{213}$, fact $\left._{214}\right\}$.

From the above self-evaluation process, it is not difficult to find that the MR-E only describes the facts and thus it is unlikely to lead to a self-promotional evaluation.

Expert evaluation is made on each element that the MR-E belongs to regarding its grade level based on the actual performance of the MR-E on the included indices. Suppose the set of grade levels is defined as $V=\left(V_{1}, \ldots, V_{Q}\right)$. For example, if $Q=5$, then the set of grade levels can be defined as $V=\left(V_{1}\right.$, $\left.\ldots, V_{5}\right)=$ (Excellent, Good, Average, Poor, Very Poor). For the performance of the MR-E on the element $c_{i j}$, expert $e_{\mathrm{n}}$ can make an evaluation based on the fact $x_{i j}$ and give the assessment $M_{i j}^{n}$ as in

$$
M_{i j}^{n}=\left(m_{i j}^{n q} \mid \sum_{q} m_{i j}^{n q}=1 ; m_{i j}^{n q}=0,1 ; q=1, \ldots, Q\right) \quad i=1, \ldots, 5 j=1, \ldots, J_{i}, n=1, \ldots, N
$$

$m_{i j}^{n q}$ describes whether the performance of the MR-E belongs to the grade level $V_{q}$ on the element $c_{i j}$ or not. Only one grade level is true in the assessment $M_{i j}^{n}$ and thus $m_{i j}^{n q}=0,1$ and $\sum_{q} m_{i j}^{n q}=1$. Consequently, the performance of the MR-E on each factor can be described as a membership distribution by integrating those performances on its included elements. On factor $C_{i}$, the membership distribution of the MR-E can be calculated by 


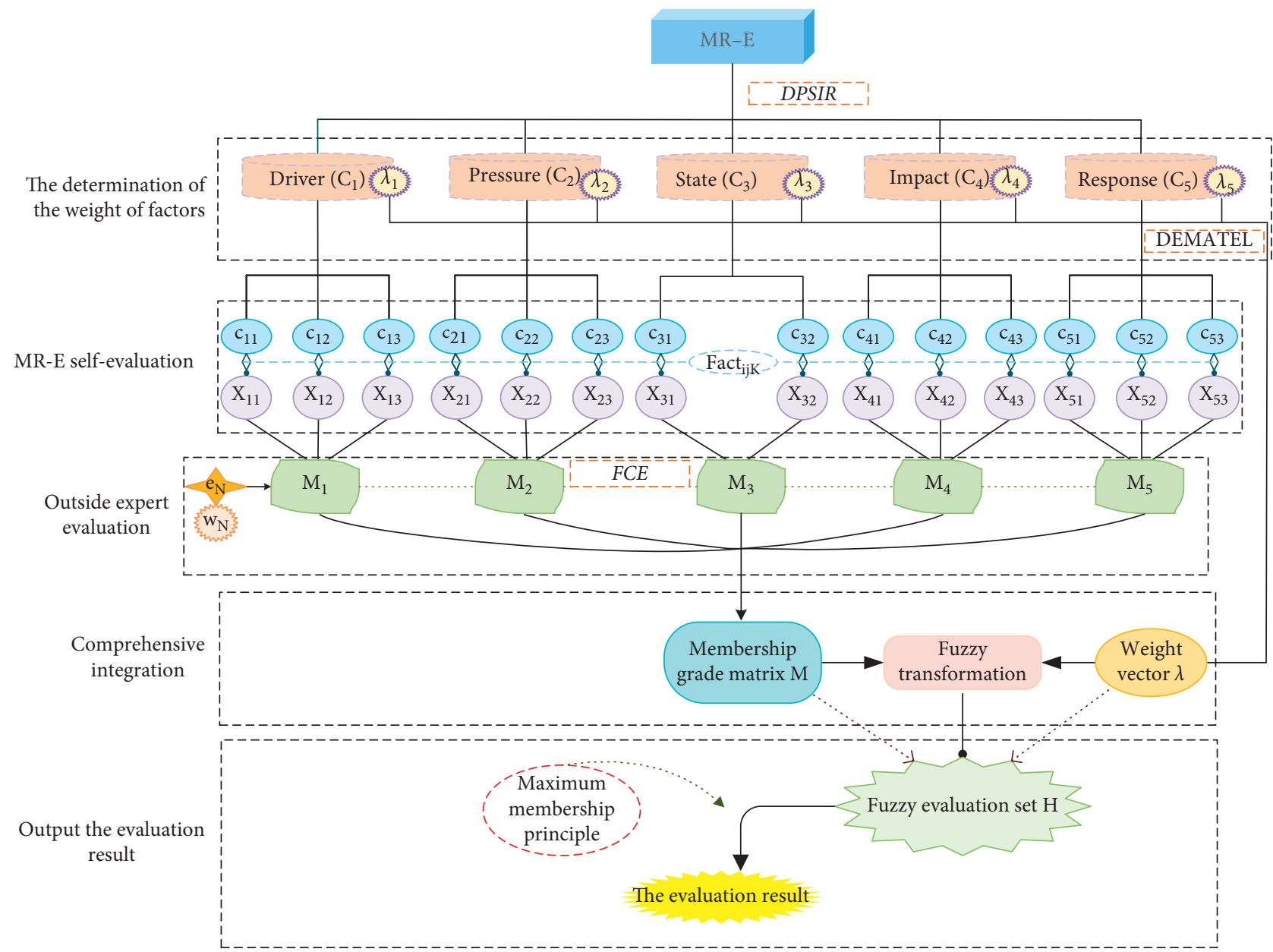

FIGURE 2: The evaluation mechanism for MRES.

$$
M_{i}^{n}=\sum_{j=1}^{J_{i}} \frac{M_{i j}^{n}}{J_{i}}=\left(M_{i}^{n q} \mid=\sum_{j=1}^{J_{i}} \frac{M_{i j}^{n q}}{J_{i}} ; q=1, \ldots, Q\right), \quad i=1, \ldots, 5, j=1, \ldots, J_{i}, n=1, \ldots, N .
$$

Note that the evaluation ability of experts may be different owing to varied, subjective experiences. Therefore, weights are frequently employed to reflect the relative importance of the different judgments given by the experts $[46,53]$. Suppose the weight of expert $e_{n}$ is $w_{n}$. The expert weight vector can be described as $W=\left(w_{n} \mid \sum_{n} w_{n}=1,0\right.$ $\left.\leq w_{n} \leq 1, n=1, \ldots, N\right)$.

3.3. Factor Weight Calculation. As mentioned in Section 1, the MRES factors may interact with each other within the complex marine ranching system. The influence that the system structure has on the system function cannot be ignored. How to determine the weights of factors by considering the interactions between the factors is a crucial problem. Fortunately, it is well-known that DEMATEL is a popular MCDM technique that can find the direct and indirect causal relationships between the factors in complicated decision-making models $[54,55]$. It has been successfully used to solve decision-making problems in a variety of situations. This study utilizes DEMATEL to determine the weights of the five factors. It is worth noting that DPSIR not only provides the five factors but also illuminates the directinfluence relationships between them, and thus, the provided relationships can be seen as the input information to DEMATEL. To avoid subjective arbitrariness as much as possible in the DEMATEL method, this study only considers whether the influencing relationship between the factors exists or not. In other words, the grade levels employed in DEMATEL are defined as 0 and 1 . The specific steps are as follows.

Step 1: Establish an initial direct-relation (IDR) matrix. According to the relations provided in the DPSIR framework, the IDR matrix of the five factors 
$\left(\mathrm{C}_{1}, \ldots, \mathrm{C}_{5}\right)$ can be established as $Z=\left[z_{i i^{\prime}}\right]_{5 \times 5}$. If there is an influence relationship in the DPSIR framework $\mathrm{C}_{i} \longrightarrow \mathrm{C}_{i^{\prime}}$, then let $z_{i i^{\prime}}=1$; otherwise, let $z_{i i^{\prime}}=0$.

Step 2: Normalize the IDR matrix. The IDR matrix is normalized by $z_{i i^{\prime}}{ }^{\prime}=z_{i i^{\prime}} / \max \left(\max _{1 \leq i^{\prime} \leq 5}\left(\sum_{i} z_{i i^{\prime}}\right)\right.$, $\left.\max _{1 \leq i \leq 5}\left(\sum_{i^{\prime}} z_{i i^{\prime}}\right)\right)$, and the normalized IDR matrix can be determined as $Z^{\prime}=\left[z_{i i^{\prime}}^{\prime}\right]_{5 \times 5}$.

Step 3: Compute the total relation matrix. To reflect the direct influence along with indirect influence, the total relation matrix is computed by $T=Z^{\prime}\left(I-Z^{\prime}\right)^{-1}=\left[t_{i i^{\prime}}\right]_{5 \times 5}$, where $I$ means the identity matrix.

Step 4: Determine the weights of factors. The weights of factors can be determined by computing the factor's influencing degree and influenced degree. The influencing degree of factor $\mathrm{C}_{i}$ is computed by $f_{i}=\sum_{i^{\prime}} t_{i i^{\prime}}$, and the influenced degree is computed by $f_{i}^{\prime}=\sum_{i^{\prime}} t_{i^{\prime} i}$. The prominence degree of factor $\mathrm{C}_{i}$ is computed by $g_{i}=f_{i}+f_{i}^{\prime}, i=1, \ldots, 5$. The weight of factor $\mathrm{C}_{i}$ can be determined by $\lambda_{i}=g_{i} / \sum_{i} g_{i}, i=1, \ldots, 5$. The weights of

$$
\begin{aligned}
& \text { factors } \quad \text { are } \\
& \lambda=\left(\lambda_{i} \mid \sum_{i} \lambda_{i}=1,0 \leq \lambda_{i} \leq 1, i=1, \ldots, 5\right) .
\end{aligned}
$$

3.4. MRES Evaluation. As mentioned in Subsections 3.2 and 3.3 , each expert can evaluate the performance level $M_{n i}$ $(\forall i, n)$ of the MR-E on factor $C_{i}$ by considering the selfevaluation results $X_{i 1}, \ldots, X_{i J_{i}}(\forall i, j)$. In addition, DEMATEL can get the weights of factors as $\lambda=\left(\lambda_{i} \mid \sum_{i} \lambda_{i}=1,0 \leq \lambda_{i} \leq 1, i=1, \ldots, 5\right)$ based on the DPSIR model. With the above information as the input, the FCE method is employed to determine the evaluation results of the MR-E on the five factors. The specific steps are as follows.

Step 1: Construct the fuzzy membership matrix. To describe the judgment information of all experts, it is necessary to construct an integrated fuzzy membership matrix. The membership function on factor $C_{i}$ can be obtained by integrating expert judgment and expert weight, which is shown as equation (3). The fuzzy membership matrix can be described as $M=\left(m_{i}^{q}\right)_{5 \times Q}$.

$$
M_{i}=\left(m_{i}^{q} \mid m_{i}^{q}=\sum_{n} w_{n} m_{n i}^{q}, \sum_{q} m_{i}^{q}=1,0 \leq m_{i}^{q} \leq 1, q=1, \ldots, Q\right), \quad i=1, \ldots, 5
$$

Step 2: Combine the factor weight $\lambda$ with the fuzzy relationship matrix $M$. To obtain the final result of the evaluated MR-E, a fuzzy operator o should be selected to integrate the evaluation performance of the MR-E on different factors, i.e., $H=M \circ \lambda=\left(h_{1}, \ldots, h_{Q}\right)$. To fully use the decision information on all factors, this study suggests the weighted average operator to make combinations, i.e., $h_{q}=\sum_{i} \lambda_{i} m_{i}^{q}, q=1, \ldots, Q$.

Step 3: Make comprehensive evaluation. Comprehensive membership vector $H$ represents the probability distribution of the comprehensive performance of the MR-E on all grade levels, and the comprehensive judgment can be obtained based on the maximum membership principle. Then, the $v_{*}$ corresponding to $h\left(v_{*}\right)=\max \left(h\left(v_{1}\right), \ldots, h\left(v_{\mathrm{Q}}\right)\right)$ is the final grade level to which the MR-E belongs.

3.5. Summarization for the MRES Evaluation. The process of the MRES evaluation is summarized as follows.

Step 1: Construct the MRES evaluation index system. Construct the evaluation index system for MRES as shown in Figure 1, which includes three levels, namely, the factor level, the element level, and the index level.

Step 2: Conduct self-evaluation. The MR-E is required to objectively evaluate the performance of marine ranching on $c_{i j}$ and give the fact set as $X_{i j}=\left\{\right.$ fact $_{i j 1}$, fact $_{i j 2}, \ldots$, fact $\left._{i j K_{i j}}\right\}, i=1, \ldots, 5, j=1$, $\ldots, J_{i}$.
Step 3: Undertake expert evaluation. According to the self-evaluation results $X_{i 1}, \ldots, X_{i J_{i}}$, expert $e_{n}$ with weight $w_{n}$ is required to evaluate the performance of the MR-E on the element $c_{i j}$ and give the assessment $M_{i j}^{n}$ as in equation (1). The membership distribution of the MR-E on factor $C_{i}$ is calculated by equation (2) and $M_{i}^{n}$ is determined, $i=1, \ldots, 5, n=1, \ldots, N$.

Step 4: Determine factor weights. The factor weight $\lambda=$ $\left(\lambda_{i} \mid \sum_{i} \lambda_{i}=1,0 \leq \lambda_{i} \leq 1, i=1, \ldots, 5\right)$ is determined by employing the DEMATEL method as in subsection 3.3.

Step 5: Conduct the MRES evaluation. Taking the membership distribution of the MR-E on factor $\mathrm{C}_{i}\left(M_{i j}^{n}, i=1, \ldots, 5, n=1, \ldots, N\right)$ and factor weight $(\lambda)$ as inputs, the final grade level of the MR-E is determined by the FCE method as in Subsections 3.4.

The MRES evaluation process is shown in Figure 3.

\section{Case Simulation Study}

4.1. Background. Shandong Blue Ocean Technology Co., Ltd. (SBOT), located in Yantai, Shandong Province, was established in December 2011. It has a registered capital of 80 million yuan, total assets of 411.99 million yuan, $260 \mathrm{em}-$ ployees, and 160,000 mu of confirmed sea area. Its business scope is the research, development, and promotion of aquatic products technology and the breeding, processing, refrigeration, sales, and tourism of sea cucumbers and other sea treasures. SBOT is an MR-E, and its marine ranching has been made a national demonstration area. In this case 


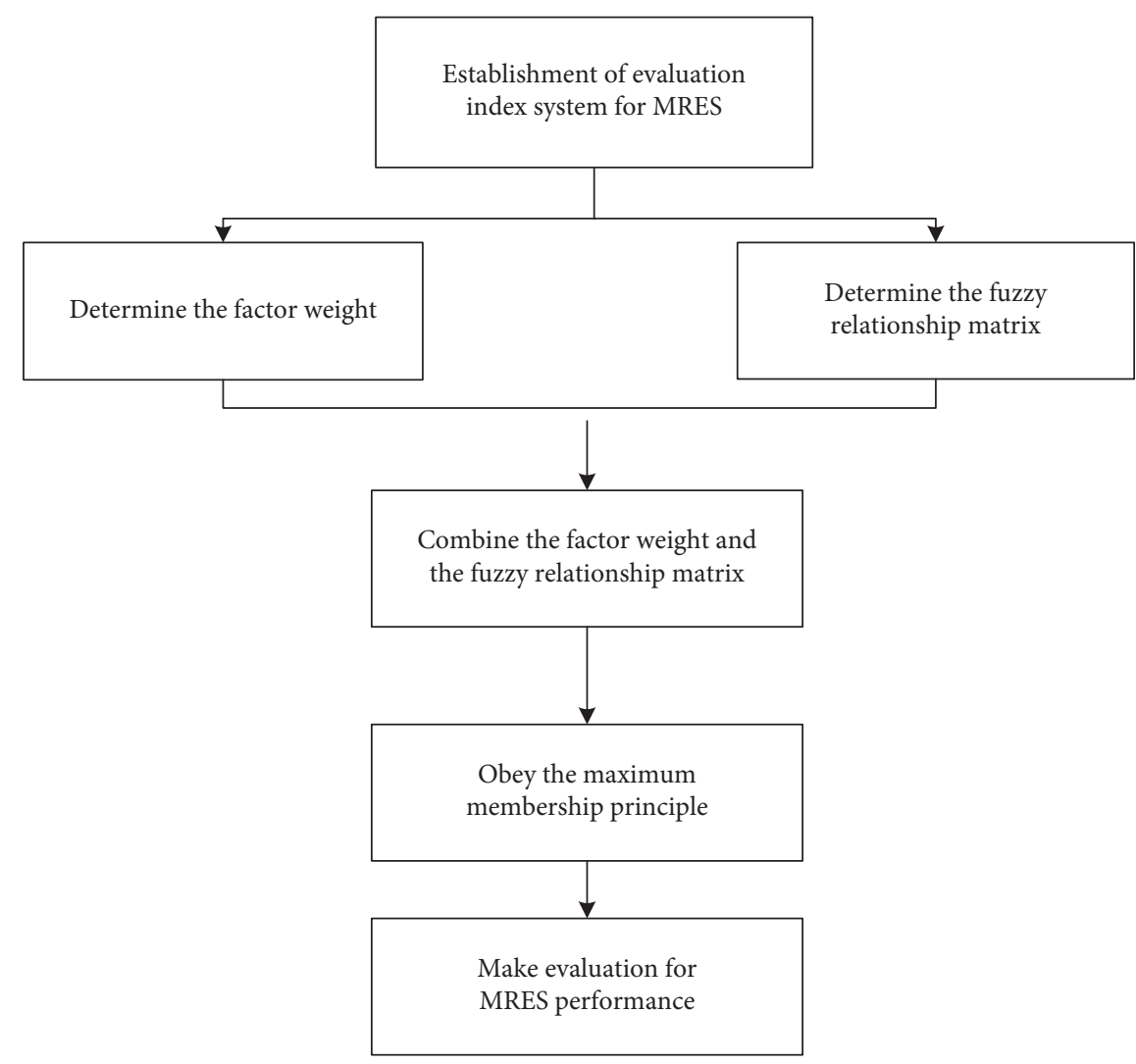

FIGURE 3: MRES evaluation framework.

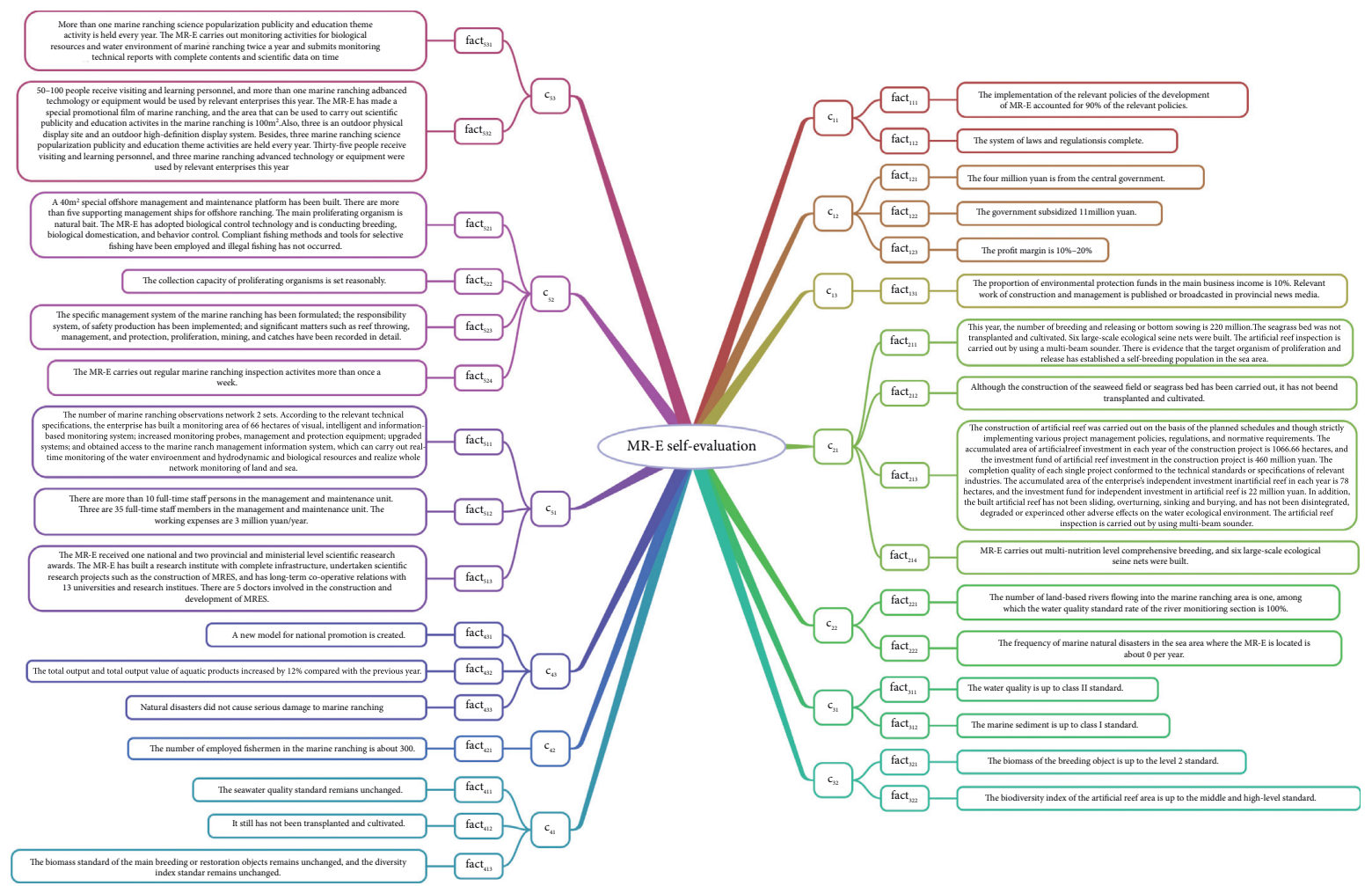

Figure 4: Self-evaluation by the MR-E. 
survey, data collection was mainly accomplished through field visits, interviews, and questionnaires during September and October in 2019.

The MR-E is evaluated by five grade levels, i.e., Excellent $\left(v_{1}\right)$, Good $\left(v_{2}\right)$, Average $\left(v_{3}\right)$, Poor $\left(v_{4}\right)$, and Very Poor $\left(v_{5}\right)$, so the set of grade levels is defined as $V=\left\{v_{1}, v_{2}, v_{3}, v_{4}, v_{5}\right\}$. We invited five experts $e_{1}, \ldots, e_{5}$ who are engaged in marine-ranching-related research at the Ocean University of China to participate in the MRES evaluation. Considering the differences in professional competence and other aspects of the five experts, the expert weight set is $W=(0.1,0.25,0.15,0.2,0.3)$.

4.2. Self-Evaluation and Expert Evaluation. The selfevaluation information plays an important role in the MRES evaluation of the MR-E. We invited the manager of SBOT to make MR-E self-evaluation. Following the same evaluation process mentioned earlier, fact ${ }_{i j K_{i j}}$ is the performance of $c_{i j K_{i j}}$, and the specifics of the MR-E are as follows.

The performance of marine ranching on $c_{i j}$ is shown in Figure 4.

Self-evaluation information of the MR-E that the MR-E manager provides according to the actual development status is as shown in Table 1. According to the self-evaluation information, the five experts invited in this paper provided the evaluation information $M_{i j}^{n}$ based on the fact $X_{i j}$ of the MR-E, as shown in Columns 4-8 in Table 1.

\subsection{Factor Weight Calculation}

(1) Confirm the direct-influence relationship between the five factors. DPSIR provides a possible influence relationship between its five factors, which can be regarded as $\left(\mathrm{C}_{1}, \mathrm{C}_{5}\right) \longrightarrow \mathrm{C}_{2}, \quad\left(\mathrm{C}_{2}, \mathrm{C}_{5}\right) \longrightarrow \mathrm{C}_{3}$, $\left(\mathrm{C}_{3}, \mathrm{C}_{5}\right) \longrightarrow\left(\mathrm{C}_{4}\right), \mathrm{C}_{4} \longrightarrow \mathrm{C}_{5}, \mathrm{C}_{5} \longrightarrow \mathrm{C}_{1}$. For example, as mentioned in Section 2, Driving $\left(\mathrm{C}_{1}\right)$ may act directly on the environment and cause Pressure $\left(C_{2}\right)$ from changes in the marine environment, and Pressure $\left(C_{2}\right)$ can cause changes in the natural system and environmental State $\left(\mathrm{C}_{3}\right)$. In order to avoid subjectivity, this paper follows the causality chain defined by DPSIR, and the DPSIR impossible influence mechanism is summarized in Figure 5.

(2) Establish the IDR matrix. The direct-influence matrix can be presented based on the causal relationship provided in the DPSIR framework. The results are shown in

$$
Z=\left[z_{i i^{\prime}}\right]_{5 \times 5}=\left[\begin{array}{lllll}
0 & 1 & 0 & 0 & 0 \\
0 & 0 & 1 & 0 & 0 \\
0 & 0 & 0 & 1 & 0 \\
0 & 0 & 0 & 0 & 1 \\
1 & 1 & 1 & 1 & 0
\end{array}\right] .
$$

(3) Normalize the IDR matrix. Follow the steps mentioned above to obtain the normalized direct- influence matrix $Z^{\prime}$ as expressed in equation (5), which shows the normalized direct-influence with their influence degrees of the five factors on each other. For example, we see that Pressure has an initial direct-influence on the State with an influence degree of 0.25 , but it has no initial direct-influence on the remaining factors.

$$
Z^{\prime}=\left[z_{i i^{\prime}}^{\prime}\right]_{5 \times 5}=\left[\begin{array}{ccccc}
0 & 0.25 & 0 & 0 & 0 \\
0 & 0 & 0.25 & 0 & 0 \\
0 & 0 & 0 & 0.25 & 0 \\
0 & 0 & 0 & 0 & 0.25 \\
0.25 & 0.25 & 0.25 & 0.25 & 0
\end{array}\right] .
$$

(4) Compute the total relation matrix. By a series of calculations, the total relations with their influence degrees between the five factors can be obtained. Equation (6) shows the total relations with their influence degrees between the five factors. For example, we see that Pressure has total relations with the Driver, Pressure, State, Impact, and Response, with influence degrees of $0.004,0.005,0.256,0.068$, and 0.017 , respectively. It is worth noting that the influence degrees between equations (5) and (6) are diffident, because equation (5) only reflects the influence degree of direct relation, whereas equation (6) reflects both the direct and the indirect relations. Taking $\mathrm{C}_{1} \longrightarrow \mathrm{C}_{3}$ for example, there is no direct-influence, but there is an indirect relation $\mathrm{C}_{1} \longrightarrow \mathrm{C}_{2} \longrightarrow \mathrm{C}_{3}$, which caused the total relation to be 0.064 .

$$
T=\left[\begin{array}{lllll}
0.001 & 0.251 & 0.064 & 0.017 & 0.004 \\
0.004 & 0.005 & 0.256 & 0.068 & 0.017 \\
0.017 & 0.021 & 0.022 & 0.273 & 0.068 \\
0.068 & 0.085 & 0.089 & 0.091 & 0.273 \\
0.273 & 0.341 & 0.358 & 0.362 & 0.091
\end{array}\right] .
$$

(5) Determine the weights of factors. Determine the weight of each factor according to the previous steps. Specifically, calculate $f_{i}$ and $f_{i}^{\prime}$ of factor $C_{i}$ and subsequently obtain the prominence $g_{i}$ and $\lambda_{i}$ of factor $\mathrm{C}_{i}$ (Table 2).

Then, the factor weight $\lambda=\left(\lambda_{1}, \lambda_{2}, \lambda_{3}, \lambda_{4}, \lambda_{5}\right)=(0.1123$, $0.1690,0.1909,0.2270,0.3008)$ is calculated by normalization of centrality. Thus, the weights of factors included in the five subsystems are ranked in the order: Response (0.3008) > Impact $(0.2270)>$ State $(0.1909)>$ Pressure $(0.1690)>$ Driver $(0.1123)$.

\subsection{MRES Evaluation}

(1) Construct the fuzzy membership matrix. Based on the quantitative self-evaluation information, five authoritative experts comprehensively evaluate factor $C_{i}$. The evaluation results are shown in columns $4-8$ of Table 1 . Then, the integrated fuzzy membership degree matrix $M$ can be obtained by 
TABLE 1: MR-E self-evaluation and experts' evaluation information form.

\begin{tabular}{|c|c|c|c|c|c|c|c|}
\hline Factor on level 1 & Element on level 2 & Fact & $e_{1}$ & $e_{2}$ & $e_{3}$ & $e_{4}$ & $e_{5}$ \\
\hline $\begin{array}{l}\text { Driver } \\
\mathrm{C}_{1}\end{array}$ & $\begin{array}{l}\mathrm{C}_{11} \\
\mathrm{C}_{12} \\
\mathrm{C}_{13} \\
\end{array}$ & $\begin{array}{c}X_{11}=\left\{\text { fact }_{111}, \text { fact }_{112}\right\} \\
X_{12}=\left\{\text { fact }_{121}, \text { fact }_{122}, \text { fact }_{123}\right\} \\
X_{13}=\left\{\text { fact }_{131}\right\}\end{array}$ & $\begin{array}{l}\text { Excellent } \\
\text { Excellent } \\
\text { Good }\end{array}$ & $\begin{array}{l}\text { Good } \\
\text { Excellent } \\
\text { Good }\end{array}$ & $\begin{array}{l}\text { Average } \\
\text { Good } \\
\text { Average }\end{array}$ & $\begin{array}{l}\text { Good } \\
\text { Good } \\
\text { Good }\end{array}$ & $\begin{array}{c}\text { Excellent } \\
\text { Excellent } \\
\text { Good }\end{array}$ \\
\hline $\begin{array}{l}\text { Pressure } \\
\mathrm{C}_{2}\end{array}$ & $\begin{array}{l}\mathrm{C}_{21} \\
\mathrm{C}_{22} \\
\end{array}$ & $\begin{array}{c}X_{21}=\left\{\text { fact }_{211}, \text { fact }_{212}, \text { fact }_{213}, \text { fact }_{214}\right\} \\
X_{22}=\left\{\text { fact }_{221}, \text { fact }_{222}\right\}\end{array}$ & & & & & \\
\hline $\begin{array}{l}\text { State } \\
\mathrm{C}_{3}\end{array}$ & & $\begin{aligned} X_{31} & =\left\{\text { fact }_{311}, \text { fact }_{312}\right\} \\
X_{32} & =\left\{\text { fact }_{321}, \text { fact }_{322}\right\}\end{aligned}$ & & $\begin{array}{c}\text { Good } \\
\text { Excellent }\end{array}$ & & & \\
\hline $\begin{array}{l}\text { Impact } \\
\mathrm{C}_{4}\end{array}$ & $\begin{array}{l}\mathrm{C}_{41} \\
\mathrm{C}_{42} \\
\mathrm{C}_{43} \\
\end{array}$ & $\begin{aligned} X_{41}= & \left\{\text { fact }_{411}, \text { fact }_{412}, \text { fact }_{413}\right\} \\
& X_{42}=\left\{\text { fact }_{421}\right\} \\
X_{43}= & \left\{\text { fact }_{431}, \text { fact }_{432}, \text { fact }_{433}\right\}\end{aligned}$ & $\begin{array}{l}\text { Average } \\
\text { Excellent } \\
\text { Average }\end{array}$ & $\begin{array}{l}\text { Excellent } \\
\text { Excellent } \\
\text { Excellent }\end{array}$ & $\begin{array}{l}\text { Excellent } \\
\text { Excellent } \\
\text { Excellent }\end{array}$ & $\begin{array}{l}\text { Good } \\
\text { Excellent } \\
\text { Good }\end{array}$ & $\begin{array}{l}\text { Good } \\
\text { Excellent } \\
\text { Good }\end{array}$ \\
\hline $\begin{array}{l}\text { Response } \\
\mathrm{C}_{5}\end{array}$ & $\begin{array}{l}\mathrm{C}_{51} \\
\mathrm{C}_{52} \\
\mathrm{C}_{53} \\
\end{array}$ & $\begin{array}{c}X_{51}=\left\{\text { fact }_{511}, \text { fact }_{512}, \text { fact }_{513}\right\} \\
X_{52}=\left\{\text { fact }_{521}, \text { fact }_{522}, \text { fact }_{523}, \text { fact }_{524}\right\} \\
X_{53}=\left\{\text { fact }_{531}, \text { fact }_{532}\right\}\end{array}$ & $\begin{array}{l}\text { Excellent } \\
\text { Excellent } \\
\text { Excellent }\end{array}$ & $\begin{array}{l}\text { Excellent } \\
\text { Excellent } \\
\text { Excellent }\end{array}$ & $\begin{array}{c}\text { Good } \\
\text { Good } \\
\text { Excellent }\end{array}$ & $\begin{array}{l}\text { Excellent } \\
\text { Excellent } \\
\text { Excellent }\end{array}$ & $\begin{array}{l}\text { Excellent } \\
\text { Excellent } \\
\text { Excellent }\end{array}$ \\
\hline
\end{tabular}

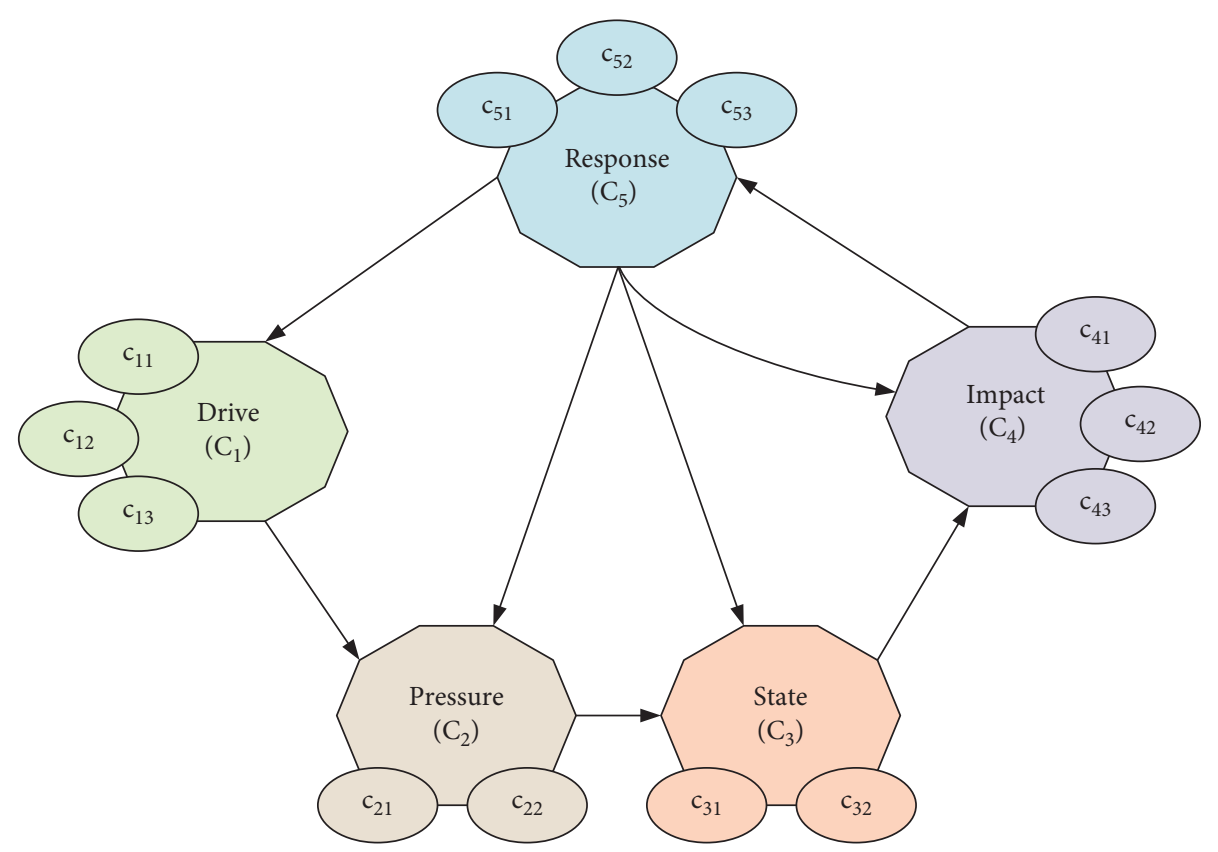

FIgURE 5: The DPSIR impossible influence mechanism.

TABLE 2: Results of DEMATEL.

\begin{tabular}{lccccc}
\hline & $\begin{array}{c}\text { Driver } \\
\left(\mathrm{C}_{1}\right)\end{array}$ & $\begin{array}{c}\text { Pressure } \\
\left(\mathrm{C}_{2}\right)\end{array}$ & $\begin{array}{c}\text { State } \\
\left(\mathrm{C}_{3}\right)\end{array}$ & $\begin{array}{c}\text { Impact } \\
\left(\mathrm{C}_{4}\right)\end{array}$ & $\begin{array}{c}\text { Response } \\
\left(\mathrm{C}_{5}\right)\end{array}$ \\
\hline$f_{i}$ & 0.3376 & 0.3504 & 0.4015 & 0.6060 & 1.4239 \\
$f_{i}$ & 0.3632 & 0.7039 & 0.7891 & 0.8104 & 0.4526 \\
$g_{i}$ & 0.7007 & 1.0543 & 1.1906 & 1.4164 & 1.8765 \\
$\lambda_{i}$ & 0.1123 & 0.1690 & 0.1908 & 0.2270 & 0.3008 \\
\hline
\end{tabular}

$$
M=\left[\begin{array}{ccccc}
0.35 & 0.55 & 0.1 & 0 & 0 \\
0.9 & 0.1 & 0 & 0 & 0 \\
0.33 & 0.67 & 0 & 0 & 0 \\
0.6 & 0.33 & 0.07 & 0 & 0 \\
0.9 & 0.1 & 0 & 0 & 0
\end{array}\right] .
$$

(2) Calculate the comprehensive evaluation value. The fuzzy operator $\circ$ is selected to integrate the weight vector $\lambda$ of the five factors with the membership matrix $M$, and finally, the results of FCE are obtained as $H=M \circ \lambda=(0.6613,0.3116,0.0271,0.0000$, $0.0000)$. It can be seen that the probability of the MRE being rated as Excellent, Good, Average, Poor, and Very poor are $66.13 \%, 31.16 \%, 2.71 \%, 0.0 \%$, and $0.0 \%$, respectively.

(3) Make comprehensive evaluation. According to the principle of maximum membership degree, the evaluation result of the MRES is Excellent.

In summary, the DEMATEL method was used to determine the factor weight, and FCE was used to determine the comprehensive evaluation result from the factor weight and the evaluation value of the factor. 
4.5. Discussion. Based on the case study, we can state that this method has the following three characteristics:

(1) The index system has a theoretical basis. The MRES index system is constructed according to the DPSIR framework (see Figure 1). Because it can reflect the concrete performance of marine ranching in five dimensions (including Driver, Pressure, State, Impact, and Response), it can systematically reflect the MRES level from the perspective of sustainable development. In the actual evaluation, the index system can be directly utilized for evaluation.

(2) The division of labor between the MR-E and the experts is clear. MR-E needs to objectively give its performance on the lowest indices in the MRES index system according to its actual situation (see Figure 4). Experts evaluate the overall performance of the MR-E on high-level factors according to the results of the self-evaluation of the MR-E (see Table 1). The MR-E and the experts can combine their advantages with a clear division of labor. The former can provide accurate decision-making information, and the latter can make scientific evaluation according to the decision-making information.

(3) The evaluation process is simple enough. Selfevaluation of the MR-E can be completed by filling out the self-evaluation report, and the content of the self-evaluation should reflect according to the index system in the self-evaluation report. Experts only need to evaluate the overall performance of the MR-E according to the self-evaluation results (see Table 1) without considering the complex mechanism of action in the MRES system. The mechanism is reflected by combining DPSIR, DEMATEL, and FCE (see Figure 4 and formulas (4)-(7)). Thus, a scientific evaluation of MRES is realized.

\section{Conclusions}

Marine ranching can enable marine food supply and effectively protect the marine ecosystem. This is one of the instruments of implementing a green development strategy. Moreover, MRES is related to national security, sea area safety, and life safety. However, few MRES evaluations have been included in the existing ecological security studies. For this reason, the present study took marine ranching as the research object, adopted three methods (DPSIR, DEMATEL, and FCE) to evaluate its ecological security, and provided an illustrative case to demonstrate the applicability of the proposed methods.

The main contributions of this study can be summarized in three aspects. First of all, the present study constructed an MRES evaluation index system. Based on field visits, interviews, questionnaires, and other ways, and by integrating social, economic, ecological, and other systems, the evaluation index system of the present study was established through the DPSIR method, which fills a research gap and provides a reference for researchers and practitioners.
Secondly, this study proposed an evaluation method for MRES. The advantage of the integration of DEMATEL and FCE is that it avoids the influence of different factors and experts' decision-making ability on the evaluation results, which makes the evaluation results more scientific and rigorous. In addition, through MR-E self-evaluation and expert evaluation, the combination of subjective and objective evaluation makes the evaluation results more credible. Thirdly, the proposed method was applied to a real case. Taking SBOT as an example, the present study elaborated on the evaluation content, enriched the MRES evaluation framework, and demonstrated the operation process of applying the methods in practice. The grade level of the evaluation results set was determined in this study. Furthermore, the evaluation process has a certain guiding integral role in the development of MRES.

It is not difficult to find that Response $\left(C_{5}\right)$ plays an important role in MRES through the weights of five factors. MR-E can take a series of positive measures to improve the quality of MRES and avoid the deterioration of ecological environment. The following managerial implications can be obtained. First, laws and regulations promulgated by the government can motivate $\mathrm{MR}-\mathrm{E}$ to take positive actions-MR-E should be aware of the environmental consequences of their actions and constantly improve the level of scientific management. Second, MR-E should make full use of the technology and knowledge provided by universities and scientific research units to promote the transformation of scientific research achievements. Third, MR-E should enhance their awareness of ecological and environmental protection and create a harmonious and sustainable corporate culture atmosphere through a series of publicity activities and training.

Although the ecological benefit of marine ranching is acknowledged, it is worth noticing that improper management of MRES will bring greater potential environmental threats to the sea area. MRES evaluation is a long-term dynamic process. Therefore, it is necessary to consider the dynamic and forward-looking aspects of MRES evaluation. The establishment of a dynamic evaluation mechanism of MRES based on subjective experiences and objective data is a valuable research direction for future work.

\section{Data Availability}

The data used to support the findings of this study are available from the corresponding author upon request.

\section{Conflicts of Interest}

The authors declare that they have no conflicts of interest.

\section{Acknowledgments}

This research was supported by the Major Program of National Social Science Foundation of China under Grant no. 18ZDA055. 


\section{References}

[1] Y. Du, B. Li, and X. Quan, "Construction and application of DPPD model for evaluating marine resources and environment carrying capacity in China," Journal of Cleaner Production, vol. 252, Article ID 119655, 2020.

[2] X. Zhou, X. Zhao, S. Zhang, and J. Lin, "Marine ranching construction and management in east China sea: programs for sustainable fishery and aquaculture," Water, vol. 11, no. 6, p. 1237, 2019.

[3] S. Kitada, "Economic, ecological and genetic impacts of marine stock enhancement and sea ranching: a systematic review," Fish and Fisheries, vol. 19, no. 3, pp. 511-532, 2018.

[4] A. L. Taylor, S. J. Nowland, M. N. Hearnden, C. A. Hair, and A. E. Fleming, "Sea ranching release techniques for cultured sea cucumber Holothuria scabra (Echinodermata: holothuroidea) juveniles within the high-energy marine environments of northern Australia," Aquaculture, vol. 465, pp. 109-116, 2016.

[5] E. Moksness and R. Støle, "Larviculture of marine fish for sea ranching purposes: is it profitable?" Aquaculture, vol. 155, no. 1-4, pp. 341-353, 1997.

[6] D. Zhang, Y. Cui, H. Zhou et al., "Microplastic pollution in water, sediment, and fish from artificial reefs around the Ma'an Archipelago, Shengsi, China," Science of The Total Environment, vol. 703, Article ID 134768, 2020.

[7] W. S. Grant, J. Jasper, D. Bekkevold, and M. Adkison, "Responsible genetic approach to stock restoration, sea ranching and stock enhancement of marine fishes and invertebrates," Reviews in Fish Biology and Fisheries, vol. 27, no. 3, pp. 615-649, 2017.

[8] E. Hadas, M. Shpigel, and M. Ilan, "Sea ranching of the marine sponge Negombata magnifica (Demospongiae, Latrunculiidae) as a first step for latrunculin B mass production," Aquaculture, vol. 244, no. 1-4, pp. 159-169, 2005.

[9] Y. Liang, Z. Zhao, G. Zhang, S. Wang, A. Wan, and Q. Liu, "Distinguishing nutrient-depleting effects of scallop farming from natural variabilities in an offshore sea ranch," Aquaculture, vol. 518, Article ID 734844, 2020.

[10] D.-H. Kim, C. K. Seung, and Y.-I. Seo, "Multi-regional economic impacts of recreational fisheries: analysis of small sea ranch in gyeong-nam Province, korea," Marine Policy, vol. 84, pp. 90-98, 2017.

[11] S. I. Lee and C. I. Zhang, "Evaluation of the effect of marine ranching activities on the tongyeong marine ecosystem," Ocean Science Journal, vol. 53, no. 3, pp. 557-582, 2018.

[12] Z.-T. Li, M.-J. Yuan, M.-M. Hu, Y.-F. Wang, and B.-C. Xia, "Evaluation of ecological security and influencing factors analysis based on robustness analysis and the BP-DEMALTE model: a case study of the Pearl River Delta urban agglomeration,” Ecological Indicators, vol. 101, pp. 595-602, 2019.

[13] H. Hao, C. Bin, M. Zhiyuan et al., "Assessing the ecological security of the estuary in view of the ecological services- A case study of the Xiamen Estuary," Ocean \& Coastal Management, vol. 137, pp. 12-23, 2017.

[14] D. Liu and Q. Chang, "Ecological security research progress in China," Acta Ecologica Sinica, vol. 35, no. 5, pp. 111-121, 2015.

[15] J. Tian and G. Gang, "Research on regional ecological security assessment," Energy Procedia, vol. 16, pp. 1180-1186, 2012.

[16] J.-Z. Gong, Y.-S. Liu, B.-C. Xia, and G.-W. Zhao, "Urban ecological security assessment and forecasting, based on a cellular automata model: a case study of Guangzhou, China," Ecological Modelling, vol. 220, no. 24, pp. 3612-3620, 2009.
[17] M. Elliott, S. J. Boyes, S. Barnard, and Á. Borja, "Using best expert judgement to harmonise marine environmental status assessment and maritime spatial planning," Marine Pollution Bulletin, vol. 133, pp. 367-377, 2018.

[18] Y. Wang and J. Pan, "Building ecological security patterns based on ecosystem services value reconstruction in an arid inland basin: a case study in Ganzhou District, NW China," Journal of Cleaner Production, vol. 241, Article ID 118337, 2019.

[19] Y. Hua, M. Yan, and D. Limin, "Land ecological security assessment for Bai autonomous prefecture of dali based using PSR model--with data in 2009 as case," Energy Procedia, vol. 5, pp. 2172-2177, 2011.

[20] Y. Chen and J. Wang, "Ecological security early-warning in central Yunnan Province, China, based on the gray model," Ecological Indicators, vol. 111, Article ID 106000, 2020.

[21] S. Li, W. Xiao, Y. Zhao, and X. Lv, "Incorporating ecological risk index in the multi-process MCRE model to optimize the ecological security pattern in a semi-arid area with intensive coal mining: a case study in northern China," Journal of Cleaner Production, vol. 247, Article ID 119143, 2020.

[22] L. Ma, J. Bo, X. Li, F. Fang, and W. Cheng, "Identifying key landscape pattern indices influencing the ecological security of inland river basin: the middle and lower reaches of Shule river basin as an example," Science of the Total Environment, vol. 674, pp. 424-438, 2019.

[23] X. Bai and J. Tang, "Ecological security assessment of tianjin by PSR model," Procedia Environmental Sciences, vol. 2, pp. 881-887, 2010.

[24] Z. Mu, S. Zeng, and P. Wang, "Novel approach to multi-attribute group decision-making based on intervalvalued pythagorean fuzzy power Maclaurin symmetric mean operator," Computers \& Industrial Engineering, Article ID 107049, 2020.

[25] J. Wang, S. Zeng, and C. Zhang, "Single-Valued neutrosophic linguistic logarithmic weighted distance measures and their application to supplier selection of fresh aquatic products," Mathematics, vol. 8, no. 3, p. 439, 2020.

[26] X. J. Gou, Z. S. Xu, W. Zhou, and E. Herrera-Viedma, "The risk assessment of construction project investment based on prospect theory with linguistic preference orderings," Economic Research-Ekonomska Istraživanja, pp. 1-23, 2020.

[27] X. Gou, Z. Xu, and W. Zhou, "Managing consensus by multi-stage optimization models with linguistic preference orderings and double hierarchy linguistic preferences," Technological and Economic Development of Economy, vol. 26, no. 3, pp. 642-674, 2020.

[28] X. J. Gou, H. C. Liao, Z. S. Xu, and F. Herrera, "Probabilistic double hierarchy linguistic term set and its use for designing a VIKOR method: The application in smart healthcare," Journal of the Operational Research Society, pp. 1-20, 2020.

[29] P. Li, J. Liu, Y. Yang, and C. Wei, "Evaluation of povertystricken families in rural areas using a novel case-based reasoning method for probabilistic linguistic term sets," Computers \& Industrial Engineering, vol. 147, Article ID 106658, 2020.

[30] W. Ruan, Y. Li, S. Zhang, and C.-H. Liu, "Evaluation and drive mechanism of tourism ecological security based on the DPSIR-DEA model," Tourism Management, vol. 75, pp. 609-625, 2019.

[31] B. Han, H. Liu, and R. Wang, "Urban ecological security assessment for cities in the Beijing-Tianjin-Hebei metropolitan region based on fuzzy and entropy methods," Ecological Modelling, vol. 318, pp. 217-225, 2015. 
[32] X. Jiang, "Urban ecological security evaluation and analysis based on fuzzy mathematics," Procedia Engineering, vol. 15, pp. 4451-4455, 2011.

[33] N. V. Solovjova, "Ecological risk modelling in developing resources of ecosystems characterized by varying vulnerability levels," Ecological Modelling, vol. 406, pp. 60-72, 2019.

[34] P. Li and C. Wei, "An emergency decision-making method based on D-S evidence theory for probabilistic linguistic term sets," International Journal of Disaster Risk Reduction, vol. 37, Article ID 101178, 2019.

[35] S. Zeng, Y. Hu, T. Balezentis, and D. Streimikiene, "A multi-criteria sustainable supplier selection framework based on neutrosophic fuzzy data and entropy weighting," Sustainable Development, vol. 28, pp. 1431-1440, 2020.

[36] Y. Du and X. Sun, "Influence paths of marine ranching ecological security in China based on probabilistic linguistic term sets and qualitative comparative analysis," International Journal of Fuzzy Systems, 2020.

[37] X. C. Zhang, C. Ma, S. F. Zhan, and W. P. Chen, "Evaluation and simulation for ecological risk based on emergy analysis and pressure-state-response model in a coastal city, China," Procedia Environmental Sciences, vol. 13, pp. 221-231, 2012.

[38] I. Mukuvari, S. K. Mafwila, and L. Chimuka, "Measuring the recovery of the northern benguela current large marine ecosystem (BCLME): an application of the DPSIR framework," Ocean \& Coastal Management, vol. 119, pp. 227-233, 2016.

[39] R. L. Lewison, M. A. Rudd, W. Al-Hayek et al., "How the DPSIR framework can be used for structuring problems and facilitating empirical research in coastal systems," Environmental Science \& Policy, vol. 56, pp. 110-119, 2016.

[40] Y. Du and X. Li, "Hierarchical DEMATEL method for complex systems," Expert Systems with Applications, vol. 167, Article ID 113871, 2020.

[41] P. K. Singh and P. Sarkar, "A framework based on fuzzy Delphi and DEMATEL for sustainable product development: a case of Indian automotive industry," Journal of Cleaner Production, vol. 246, Article ID 118991, 2020.

[42] M. Dalvi-Esfahani, A. Niknafs, D. J. Kuss, M. Nilashi, and S. Afrough, "Social media addiction: applying the DEMATEL approach," Telematics and Informatics, vol. 43, Article ID 101250, 2019.

[43] Y.-W. Du and W. Zhou, "New improved DEMATEL method based on both subjective experience and objective data," Engineering Applications of Artificial Intelligence, vol. 83, pp. 57-71, 2019.

[44] J. Cheng and J.-p. Tao, "Fuzzy comprehensive evaluation of drought vulnerability based on the analytic hierarchy process," Agriculture and Agricultural Science Procedia, vol. 1, pp. 126-135, 2010.

[45] Z.-H. Zou, Y. Yun, and J.-N. Sun, "Entropy method for determination of weight of evaluating indicators in fuzzy synthetic evaluation for water quality assessment," Journal of Environmental Sciences, vol. 18, no. 5, pp. 1020-1023, 2006.

[46] W. Li, W. Liang, L. Zhang, and Q. Tang, "Performance assessment system of health, safety and environment based on experts' weights and fuzzy comprehensive evaluation," Journal of Loss Prevention in the Process Industries, vol. 35, pp. 95-103, 2015.

[47] G. Zheng, K. Li, W. Bu, and Y. Wang, "Fuzzy comprehensive evaluation of human physiological state in indoor high temperature environments," Building and Environment, vol. 150, pp. 108-118, 2019.
[48] R. C. de Sousa-Felix, L. C. C. Pereira, W. N. Trindade, I. P. de Souza, R. M. Da Costa, and J. A. Jimenez, "Application of the DPSIR framework to the evaluation of the recreational and environmental conditions on estuarine beaches of the Amazon coast," Ocean \& Coastal Management, vol. 149, pp. 96-106, 2017.

[49] M. Elliott, D. Burdon, J. P. Atkins et al., "And DPSIR begat DAPSI (W) R (M)!-a unifying framework for marine environmental management," Marine Pollution Bulletin, vol. 118, no. 1-2, pp. 27-40, 2017.

[50] X. Li, H. Li, D. Liu et al., "Connotation analysis and evaluation index system construction of regional agricultural soil and water resource composite system harmony," Journal of Cleaner Production, vol. 263, Article ID 121438, 2020.

[51] W. $\mathrm{Lu}, \mathrm{C} . \mathrm{Xu}, \mathrm{J} . \mathrm{Wu}$, and $\mathrm{S}$. Cheng, "Ecological effect assessment based on the DPSIR model of a polluted urban river during restoration: a case study of the Nanfei River, China," Ecological Indicators, vol. 96, pp. 146-152, 2019.

[52] P. Ma, G. Ye, X. Peng, J. Liu, J. Qi, and S. Jia, “Development of an index system for evaluation of ecological carrying capacity of marine ecosystems," Ocean \& Coastal Management, vol. 144, pp. 23-30, 2017.

[53] Y. Du and J. Zhong, "Generalized combination rule for evidential reasoning approach and Dempster-shafer theory of evidence," Information Sciences, vol. 547, pp. 1201-1232, 2021.

[54] C. Bai, J. Sarkis, and Y. Dou, "Constructing a process model for low-carbon supply chain cooperation practices based on the DEMATEL and the NK model," Supply Chain Management: An International Journal, vol. 22, no. 3, 2017.

[55] J. Kaur, R. Sidhu, A. Awasthi, S. Chauhan, and S. Goyal, “A DEMATEL based approach for investigating barriers in green supply chain management in Canadian manufacturing firms," International Journal of Production Research, vol. 56, pp. 1-2, 2018. 